\title{
Auszug aus der Bibliotheks-Ordnung
}

§ I. Die Bibliothek ist wochentäglich von ro Uhr morgens bis $10 \mathrm{Uhr}$ abends unentgeltlich geöffnet.

\$2. Die Benutzung des Lesesaals ist jedem Erwachsenen gestattet, der sich auszuweisen vermag.

\$ 4. Im Lesezimmer ist die gröfste Ruhe $z u$ beobachten, laute Unterhaltungen und sonstige Störungen sind $z u$ vermeiden.

\$ 9. Das $\mathrm{Pausen}$ ist $\mathrm{nicht}$ gestattet. -- In einzelnen besonderen Fällen kann der aufsichtführende Beamte ausnahmsweise die Erlaubnis erteilen, mit dem Bleistift zu pausen.

\$ 10. Zum Aufstellen der Bücher und Blätter beim Abzeichnen sind die auf den Tischen befindlichen Gestelle zu benutzen.

\$ I I. Der Gebrauch der $\mathrm{T}$ in $\mathrm{t}$ e ist nur an ein em bestimmten Tisch aus den dort anfgestellten Tintenfässern gestattet.

\$ 12. Zur Anfertigung farbiger Kopien dürfen nur Wasserfarben unter Benutzung der vorhandenen $T$ usch gläser verwendet werden.

\$ 14. Die Bibliotheksbeamten sind angewiesen, auf die Schonung der Bücher und einzelnen Blätter und insbesondere darauf zu halten, dafs die Blätter nicht mit Handschuhen oder angefeuchteten Fingern berührt werden. - Eine Wascheinrichtung befindet sich auf dem Vorflur.

8 I5. Wer die ihm zur Benutzung übergebenen Bücher etc. beschädigt, ist zum Ersatz des Schadens nach der Schätzung des Kunstgewerbe-Museums verpflichtet.

\$ I7. Die Bibliothekswerke sollen soweit als irgend thunlich im Lesezimmer benutzt und nur ausnahsweise verliehen werden.

\$ I 8. Nicht verliehen werden: Handschriften, Handzeichnungen, Ornamentstiche, kostbare Bilderwerke, seltene Werke, Prachtbände, schwere Folianten, Wörterbücher, Encyklopädien, die geläufigen Hand- und Lehrbücher, alle erfahrungsgemäfs im Lesezimmer zum häufigen Gebrauch erforderlicheo Werke und alle noch nicht gebundenen Bücher. 